\title{
Hay-Wells Syndrome
}

\section{Gurubacharya SM${ }^{1}$, Subedi $K^{2}$, Aryal DR ${ }^{3}$}

${ }^{1}$ Dr. Simi Mishra Gurubacharya, Registrar, ${ }^{2}$ Dr. Kalpana Subedi, Consultant Paediatrician. ${ }^{3}$ Dr. Dhan Raj Aryal, Unit Chief and Consultant Paediatrician, NICU, Paropakar Maternity and Women's Hospital (Prasuti Griha), Thapathali, Kathmandu, Nepal.

Address for Correspondence: Dr. Simi Misra Gurubacharya. E-mail: sm_pul@rediffmail.com

\section{The Case}

full-term baby was born to non-consanguinous

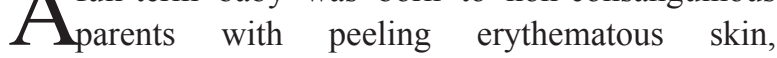
coarse, sparse hair and eyelashes, microphthalmia, ankyloblepharon, hypertelorism, cleft-lip, cleft-palate, broad nasal bridge, dystrophic nails and palmo-plantar hyperkeratosis (Fig.1, 2).The diagnosis of Hay Wells Syndrome was made.

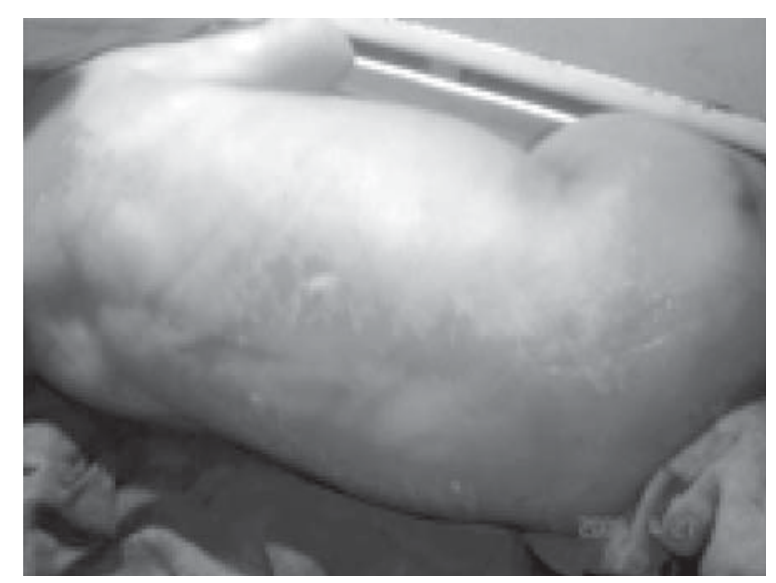

Fig 1: Showing a Neonate with Peeling Skin.

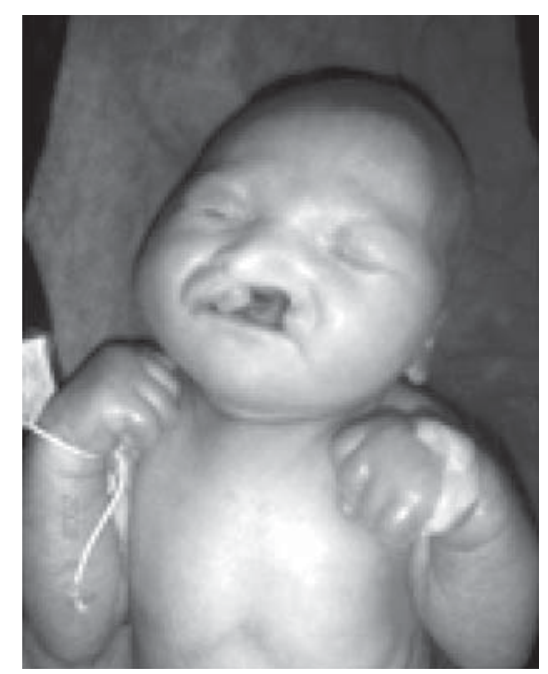

Fig 2: Showing a Neonate with Ankyloblepharon, Cleft Lip and Palate.
Hay wells syndrome is also called as ankyloblephanectodermal dysplasia-clefting syndrome (AEC).It is a rare inherited disorder, one of at least 150 known types of ectodermal dysplasia. It is an autosomal dominant trait, caused by mutations in the p63 gene in the majority of cases $^{1}$.The abnormalities commonly found are wiry and sparse hair to alopecia, broadened nasal bridge, maxillary hypoplasia, cleft palate, cleft lip or both, hypodontia to partial anodontia, ankyloblepharon filiforme adnatum, palmar and plantar keratoderma, peeling erythematous eroded skin at birth, hypohidrosis, hyperpigmentation, absent/dystrophic nails, micrognathia, retrognathia and recurrent scalp infections. Occasionally, there can be deafness, atretic external auditory canal and cup shaped auricles ${ }^{2,3}$. Several clinical syndromes'are characterized by ectodermal dysplasia in association with clefting of the lip and /or palate. The three most commonly recognized entities are: the EEC syndrome (ectrodactyly-ectodermal dysplasia-clefting syndrome); the Rapp-Hogkin syndrome with ectodermal Dysplasia, cleft lip/palate, mid facial hypoplasia; and the Hay-Wells or AEC syndrome ${ }^{4}$. The presence of ankyloblepharon distinguishes AEC syndrome from other ectodermal dysplasias.

\section{References}

1. Cabiling DS, Yan AC, McDonald-McGim DM, Zackai EH, Kirschner RE. Cleft lip and palate repair in Hay-Wells/Ankyloblepharon Ectodermal Dysplasia- Clefting syndrome. Cleft Palate Craniofacial J.2007 May; 44(3).335-339.

2. Jones LK. Hay-Well's Syndrome of Ectodermal Dysplasia.In: Smith's Recognisable patterns of Human Malformation, $5^{\text {th }}$ edn.W.B.Saunders Company, 1997; pp 296-297.

3. Fosko SW, StennKS, Bolognia JL.Ectodermal dysplasias associated with clefting: significance of scalp dermatitis.J Am Acad Dermatol.1992 Aug; 27(2 Pt 1):249-256.

4. Vanderhooft SL, Stephen MJ, Sybirl VP.Severe skin erosions and scalp infections in AEC syndrome. Pediatr Dermatol.1993 Dec; 10(4):334-340. 